\title{
La Revolución rusa en el cine: un análisis comparativo
}

MiKel BUENO URRITZELKI

Universidad Pública de Navarra

\begin{abstract}
Resumen
El presente trabajo es un ensayo acerca de las revoluciones que se dieron en Rusia en el año 1905 y las de febrero y octubre de 1917. El análisis se sustenta en filmografía conmemorativa realizada en la Unión Soviética en las décadas de 1920 y 1930. Se incluyen también dos producciones estadounidenses muy posteriores en el tiempo, con las cuales se hace una comparativa.
\end{abstract}

Palabras clave: cine, revolución rusa, Octubre, URSS

\begin{abstract}
The present work is an essay on the revolutions that occurred in Russia in the year 1905 and the February and October 1917. The analysis is bassed on commemorative catalogue of films made in the Soviet Union in the decades of 1920 and 1930. Two very subsequent American productions are also included in time, makes a comparison.
\end{abstract}

Keywords: film, Russian Revolution, October, USSR.

\section{Introducción}

La Revolución rusa de octubre de 1917 es, sin lugar a dudas, el acontecimiento más transcendental del pasado siglo XX. Dicho suceso solamente es comparable en importancia con la caída del Muro de Berlín en 1989, con la posterior desintegración de los países que conformaban el denominado «socialismo real» y la implosión de la Unión de Repúblicas Socialistas Soviéticas (URSS) en 1991, surgida en 1922 después de la guerra civil que vivió Rusia tras los sucesos de 1917. No es por ello extraño que el prestigioso historiador Eric Hobsbawm acuñase el término "corto siglo XX" y lo enmarcase entre los años 1917 y 1989. Todas las grandes convulsiones que se vivieron 
durante el pasado siglo, a excepción de la I Guerra Mundial y de la Revolución Islámica en Irán de $1979^{1}$, tuvieron como una de sus causas principales la Revolución liderada por Lenin: desde la II Guerra Mundial hasta la Guerra Fría, que condicionó la política internacional, pasando por el periodo de descolonización y las diversas revoluciones socialistas acaecidas en Asia, África y América.

\section{Los prolegómenos de la Revolución de Octubre: el "ensayo general” de 1905}

Se ha escrito mucho acerca de la idoneidad de una revolución socialista en Rusia debido al atraso en el que se encontraba debido a las políticas del régimen zarista, las cuales mantenían a Rusia en una sociedad preindustrial. No obstante, ya hubo quienes décadas antes de la revolución de 1905 vieron en Rusia la vanguardia de la revolución europea. Karl Marx y Friedrich Engels afirmaron, en el prólogo de una edición en ruso del Manifiesto Comunista en 1882, que Rusia formaba «la avanzada del movimiento revolucionario de Europa $»^{2}$. No fue una afirmación baladí viniendo de ambos pensadores, teniendo en cuenta además que Marx comenzó a estudiar ruso en $1869^{3}$.

La importancia de la Revolución de 1905 no es únicamente debido al levantamiento popular que vivió Rusia en contra del zar y la subsiguiente represión inmortalizada con la matanza del 9 de enero contra una manifestación pacífica, en lo que se conoce como «Domingo Sangriento». La marcha, disuelta con fuego real y con cientos de muertos y heridos, reclamaba una Asamblea Constituyente elegida por sufragio universal ${ }^{4}$. Esa insurrección popular «implicó el despertar a la vida política de una parte de los súbditos, incentivados por las transformaciones económicas, políticas y sociales que estaban en marcha» ${ }^{5}$.

Tanto este suceso como las manifestaciones y huelgas que le siguieron a lo largo del año obligaron al zar Nicolás II a realizar reformas liberales, tales como el reconocimiento de la libertad de prensa, asociación y reunión, así como una amnistía, la ampliación del derecho de voto a mayores sectores de la población y otorgar mayores poderes a la Duma, el parlamento ruso, que hasta entonces carecía de atribuciones, debido a su carácter meramente consultivo ${ }^{6}$.

Estos sucesos de 1905 estuvieron presentes en la realización filmográfica de la URSS en la década de 1920. Prueba de ello es la película de Serguéi Eisenstein La huelga rodada en 1924. Eisenstein afirmó que «La huelga llevó la acción colectiva y de masas a la pantalla, en contraste con el individualismo y el drama del 'triángulo' del cine burgués. Ninguna pantalla había mostrado antes una imagen de acción colectiva (...). Pero nuestro entusiasmo dio lugar a una representación 'unilateral' de las masas y de lo 'colectivo'; unilateral porque el 'colectivismo' implica el máximo desarrollo del individuo dentro de lo 'colectivo', una concepción que se opone de un modo

\footnotetext{
${ }^{1}$ Como afirma Hobsbawm, "la novedad de esta revolución era ideológica. Casi todos los fenómenos considerados revolucionarios hasta esta fecha habían seguido la tradición, la ideología y en líneas generales el vocabulario de las revoluciones occidentales desde 1789. Más en concreto, las de alguna variante de la izquierda laica, principalmente socialista o comunista. (...) La revolución iraní fue la primera realizada y ganada bajo la bandera del fundamentalismo religioso y la primera que reemplazó el antiguo régimen por una teocracia populista". En HOBSBAWM, E., 1994, Historia del siglo XX, Ed. Crítica, Buenos Aires, pág. 453.

${ }^{2}$ MARX, K. y ENGELS, F., 1987, El manifiesto comunista, ALBA, Madrid, pág. 37.

${ }^{3}$ Ibíd., pág. 26.

${ }^{4}$ DE PABLO, S. (ed.), La historia a través del cine: La Unión Soviética, EHU/UPV, Zarautz, pág. 21.

${ }^{5}$ SABORIDO, J., 2006, La revolución rusa, Ed. Dastin, Madrid, pág. 40.

${ }^{6}$ TAIBO, C., 2010, Historia de la Unión Soviética 1917-1991, Alianza Editorial, Madrid, pág. 27.
} 
irreconciliable con el individualismo burgués. A nuestras primeras películas de masas les faltaba este significado más profundo...» ${ }^{7}$.

Otra película ambientada en los acontecimientos revolucionarios de 1905 es $E l$ Acorazado Potemkin, también dirigida por Eisenstein, encargada por el gobierno de la URSS en el vigésimo aniversario de la sublevación de los marineros, y que junto con Octubre es, probablemente, el largometraje más conocido de Eisenstein.

En un principio la idea original fue realizar una película que narrase los acontecimientos más importantes, y cuyo título sería Año 1905. Este largometraje se concibió como «un gran fresco dividido en ocho episodios, empezando por el final de la guerra rusojaponesa y el 'Domingo Sangriento' y acabando por el aplastamiento en diciembre de la insurrección de Krasnopresnia, un barrio de Moscú» ${ }^{8}$. No obstante, por cuestiones económicas y del tiempo disponible para la grabación, la película se centró exclusivamente en los acontecimientos del Potemkin y, como consecuencia, no solo se cambió el argumento, reduciéndolo a un único hecho histórico de la Revolución de 1905, sino también el título.

El Acorazado Potemkin narra la sublevación de los marineros contra la oficialidad zarista en junio de 1905 y se enmarca en todos los sucesos que ocurrieron durante ese año en Rusia. El hecho que desencadenó el motín fue la negativa de la tripulación a comer carne putrefacta. Tras ello, el capitán ordena a la tripulación formar en cubierta y amenaza con la horca a los marineros. Cuando un grupo de ellos iba a ser fusilado, tanto los marineros como la guardia se amotinan y toman el poder del buque ${ }^{9}$.

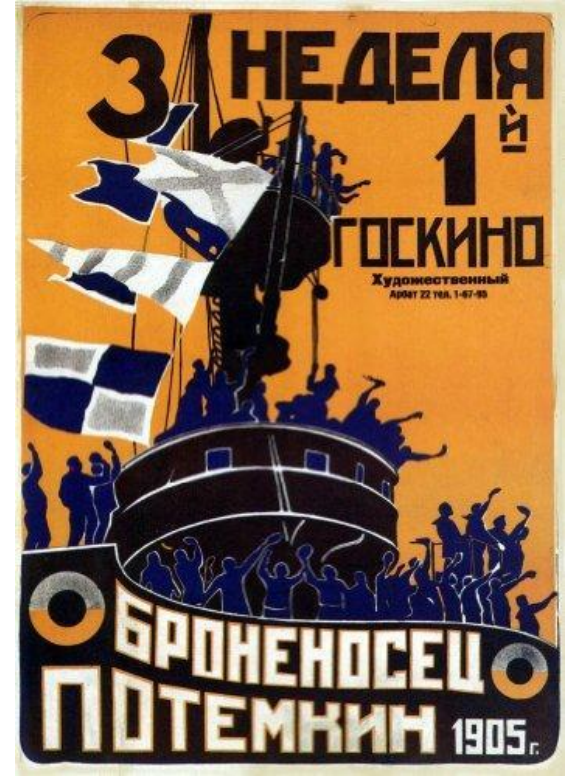

El Acorazado Potemkin

Pese a ser una película que narra acontecimientos históricos, los sucesos que se ven en las secuencias de la «escalinata de Odesa» y la compasión de la gente que suministraba comida a los amotinados, «en realidad fueron los compañeros revolucionarios los que cumplieron con su obligación en tierra y enviaron alimentos al barco de guerra. Asimismo, los demás barcos de la flota no saludaron al Potemkin como ocurre al final de la película» ${ }^{10}$. Estas invenciones, así como otras que ocurren a lo largo de la película pudieron ser realizadas para conmover al espectador y crear un ambiente más propicio para el mensaje que se quería lanzar, en donde el heroísmo, la camaradería y la solidaridad estuviesen presentes.

En la película, en los sucesos de la escalinata se observan escenas desgarradoras, avalanchas de gente, muertos es la escalera y niños aplastados ante el avance del ejército que termina disparando contra una multitud que huye desesperadamente. Como respuesta, desde el Potemkin se dispara contra el teatro de Odesa, donde se hallaba es Estado Mayor ${ }^{11}$. No obstante, y aunque la gente pensó que se trataba de un suceso real,

\footnotetext{
${ }^{7}$ BERGAN, R., 2001, Serguéi Eisenstein. Una vida en conflicto, Ed. Alba, Barcelona, pág. 123.

${ }^{8}$ BERGAN, op. cit., pág. 128

${ }^{9}$ El Acorazado Potemkin, dirigida por Serguéi Eisenstein, URSS, 1925, 77 min., secuencia: 05:03 a 23:32.

${ }^{10}$ BERGAN, op. cit., pág. 141.

${ }^{11}$ El acorazado Potemkin, op. cit., secuencia: 47:02 a 53:59.
} 
«la matanza nunca existió» ${ }^{12}$. Eisenstein siempre «se enorgulleció de haber creado (o imaginado)» ${ }^{13}$ los sucesos de la escalinata de Odesa.

El acontecimiento de la escalinata tuvo lugar en una zona cercana al puerto. Pese a que Eisenstein no se ciñe estrictamente al hecho histórico, no se desvirtúa tal acontecimiento ya que «la mezcla caótica del pueblo que huye despavorido al ver el avance de los cosacos se recoge tanto en planos generales y primeros planos en los que las figuras nos muestran el terror que experimentan en esos momentos y su impotencia» ${ }^{14}$. La función de este largometraje es «glorificar a la Revolución de Octubre, presentar al pueblo como protagonista de estas jornadas, educar a la nación en la nueva realidad socialista» ${ }^{15}$.

Existe una relación muy estrecha entre La huelga y El Acorazado Potemkin y es que los que los crueles jefes de la primera película se transforman en los represivos oficiales navales en la segunda; de igual modo que los obreros son sustituidos por los marineros ${ }^{16}$, haciendo una clara referencia a la lucha de clases. Los actores que representan a los jefes y a los oficiales harán lo propio en Octubre encarnando a «los líderes del Gobierno Provisional; por su parte en las tres películas los obreros, los marineros y los activistas bolcheviques luchan noblemente por su libertad, recibiendo cada vez la represión gubernamental a cargo de la policía o los soldados; en el primer caso el conflicto acaba en derrota, en el segundo, en triunfo parcial y, en el tercero, en victoria» ${ }^{17}$.

Lenin llegó a afirmar que la Revolución de 1905 fue «una revolución burguesa realizada con medios proletarios» ${ }^{18}$. Tras ese año convulso el zar tuvo como objetivo la creación de «un campesinado conservador, al tiempo que incrementaba la productividad agrícola iniciando decididamente una política similar a los enclosures británicos. La comuna campesina sería dividida sistemáticamente en parcelas privadas para beneficio de una clase de grandes campesinos de mentalidad comercial, los kulaks» ${ }^{19}$. Además del análisis de Lenin, lo que había demostrado dicha revolución es que el zarismo era un régimen al cual podía derrotarse $\mathrm{e}^{20}$.

En definitiva, la revolución de 1905 «tuvo un carácter mixto. Fue una revuelta de los liberales y constitucionalistas burgueses contra una autocracia arbitraria y anticuada. Fue una revuelta obrera, desatada por la atrocidad del 'domingo sangriento', y que condujo a la elección del primer soviet de diputados obreros de Petrogrado. Fue una extensa revuelta campesina, espontánea y carente de coordinación, a menudo extremadamente cargada de resentimiento y violencia ${ }^{21}$. Trotski al analizar los acontecimientos de 1905 afirma que éstos fueron el «ensayo general que había de preceder a la revolución de $1917 \gg^{22}$.

Para la caída del zar hubo que esperar hasta febrero de 1917.

\footnotetext{
12 BERGAN, op. cit., pág. 141.

${ }^{13}$ Ibíd., pág. 338.

${ }^{14}$ DE PABLO, op. cit., pág. 35.

${ }^{15}$ DE PABLO, op. cit., pág. 36.

${ }^{16}$ Ibíd., pág. 139

${ }^{17}$ BERGAN, op. cit., pág. 166.

${ }^{18}$ HOBSBAWM, E., 2009, La era del imperio. 1875-1914, Ed. Crítica, Barcelona, pág. 306.

${ }^{19}$ Ibíd., pág. 308.

${ }^{20}$ Ibíd., pág. 307.

${ }^{21}$ CARR, E.H., 2009, La revolución rusa. De Lenin a Stalin (1917-1929), Alianza Editorial, Madrid, pág. 12.

${ }^{22}$ TROTSKY, L., "1905", Mi vida, http://www.marxists.org/espanol/trotsky/1930s/mivida/index.htm (consultado 10/02/2014).
} 


\section{7: El año del triunfo revolucionario. De Febrero a Octubre}

Con la entrada del Imperio Ruso en la Gran Guerra de 1914, el zar Nicolás II firmó, sin saberlo, su sentencia. Las consecuencias producto de la guerra le costaron el cargo y tras la Revolución de Octubre la vida. El descontento popular se acrecentó debido al largo periodo de guerra, a las derrotas militares $\mathrm{y}$, por supuesto, al desabastecimiento que provocó la contienda.

En febrero de 1917 en Petrogrado «la situación no podía ser más propicia para un movimiento revolucionario: a las protestas obreras por la escasez de alimentos se sumaban la reducción de la producción industrial, la disolución del poder gubernamental y las malas noticias que llegaban de los frentes de batalla. Entre el $23 \mathrm{y}$ el 25 de febrero las huelgas y las manifestaciones se extendieron, y el día 26 se produjo una sangrienta represión por parte del ejército; a las pocas horas, sin embargo, la guarnición de la capital confraternizaba con los huelguistas. El 2 de marzo, el zar abdicaba y se formaba un Gobierno provisional que, compuesto mayoritariamente por miembros del partido de los kadetes ${ }^{23}$, declaró una amnistía y se comprometió a respetar las libertades y a convocar una asamblea constituyente producto de la libre elección popular. (...) La escasa fortaleza del Gobierno provisional era, de cualquier modo, evidente. Se puso de manifiesto en particular cuando le hizo sombra otra institución, el soviet de Petrogrado, que en los meses siguientes permitiría que obreros, soldados e intelectuales radicales ejerciesen una poderosa influencia. (...) Obligados a depositar toda su atención en la guerra, los sucesivos gobiernos provisionales apenas acertaron a mitigar las graves tensiones internas que se hacían notar en la sociedad rusa» ${ }^{24}$.

Antonio Gramsci realizó un análisis de lo que estaba ocurriendo en Rusia y lo que debería ser, según él, una verdadera revolución. Afirmó en abril de 1917 que la revolución de febrero había «destruido al autoritarismo y lo ha sustituido por el sufragio universal, extendiéndolo también a las mujeres. Ha sustituido el autoritarismo por la libertad; la Constitución por la voz libre de la conciencia universal. (...) El proletariado industrial está preparado para el cambio incluso culturalmente; el proletariado agrícola, que conoce las formas tradicionales del comunismo comunal, está igualmente preparado para el paso a una nueva forma de sociedad. Los revolucionarios socialistas no pueden ser jacobinos; en Rusia tienen en la actualidad la única tarea de controlar que los organismos burgueses (la Duma, los Zemtsvo ${ }^{25}$ ) no hagan jacobinismo para deformar la respuesta del sufragio universal y servirse del hecho violento para sus intereses» ${ }^{26}$. Es una reflexión interesante, realizada por uno de los grandes pensadores comunistas de la época, realizada en medio de un periodo turbulento.

Para el historiador E. H. Carr en febrero de 1917 estalló «la revolución más violenta de todos los tiempos. En unas semanas la sociedad se deshace de todos sus dirigentes: el monarca y sus hombres de leyes, la policía y los sacerdotes, los propietarios y los funcionarios, los oficiales y los amos» ${ }^{27}$. En definitiva, Rusia vio

\footnotetext{
${ }^{23}$ Se les denominaba así, de acuerdo con las iniciales del nombre del Partido Demócrata Constitucional (K.D. en ruso). Cuando en marzo de 1917 estalló la revolución, fueron los kadetes los que formaron el primer gobierno provisional. En REED, J., 2009, Diez días que estremecieron el mundo, Ed. Diario Público, pág. 21.

${ }^{24}$ TAIBO, op. cit., Págs. 31-32.

${ }^{25}$ Zemtsvo fue una forma de gobierno local instituido durante las grandes reformas liberales realizadas en el Imperio ruso por el zar Alejandro II de Rusia. La idea de este sistema fue desarrollada por Nikolái Miliutin. Las primeras leyes sobre los zemstvos se promulgaron en 1864. Tras la Revolución de octubre de 1917 el sistema de zemstvos fue abolido y sustituido por el de soviets o consejos obreros provinciales

${ }^{26}$ GRAMSCI, A., 1917, Notas sobre la revolución rusa, en http://www.marxists.org/espanol/gramsci/abr1917.htm (consultado el 17/02/2014).

${ }^{27}$ CARR, E. H., 1985, 1917. Antes y después (la revolución rusa), Ed. Sarpe, Madrid, pág. 10.
} 
como se realizaba una revolución burguesa en uno de los últimos imperios que quedaban en Europa, de los cuales no quedaría ninguno en pie tras el fin de la Gran Guerra en 1918.

Esta vorágine propició la vuelta del exilio de Lenin, líder de los bolcheviques, quien en enero de 1917 creía que la revolución estaba aún muy lejana, y que los dirigentes bolcheviques no la verían materializarse. Con su retorno a Rusia promulgó las famosas Tesis de Abril en donde describió lo sucedido afirmando que «la peculiaridad del momento actual en Rusia consiste en el paso de la primera etapa de la revolución, que ha dado el poder a la burguesía por carecer el proletariado del grado necesario de conciencia y de organización, a su segunda etapa, que debe poner el poder en manos del proletariado y de las capas pobres del campesinado ${ }^{28}$. Lenin afirmaba que el Gobierno Provisional, en manos de la burguesía, no era sino el enemigo de los soviets ya que representaba a una clase diferente.

Eisenstein narra en Octubre de forma vibrante la espera y posterior recibimiento que realiza el pueblo de Petrogrado, el 3 de abril en la Estación de ferrocarril Finlandia, a Lenin, que regresaba del exilio. Una vez en la ciudad, y ante la multitud que fue a recibirle, Lenin realiza un acalorado mitin, reforzado en la escenografía con un fuerte viento, donde lanza las proclamas centrales: ningún apoyo al Gobierno Provisional debido a su carácter burgués; la necesidad de una revolución socialista; y la famosa proclama de «paz, pan y tierra» ${ }^{29}$. Estas ideas fundamentales, básicas para los revolucionarios bolcheviques, son las conocidas como Tesis de Abril anteriormente mencionadas.

Este mismo acontecimiento histórico es contado de forma diferente en la teleserie estadounidense Stalin, en la que aparece el recibimiento a Lenin en la misma estación, aunque, si bien sigue siendo caluroso, solo se muestra el interior de la estación y con la presencia de muchos de los dirigentes bolcheviques esperándole y, a diferencia de Octubre, intercalando la secuencia con imágenes reales de época. También en esta película Lenin aparece realizando el mitin de las Tesis. A esto se suman imágenes, también de época, de Lenin y de la toma del Palacio de Invierno ${ }^{30}$.

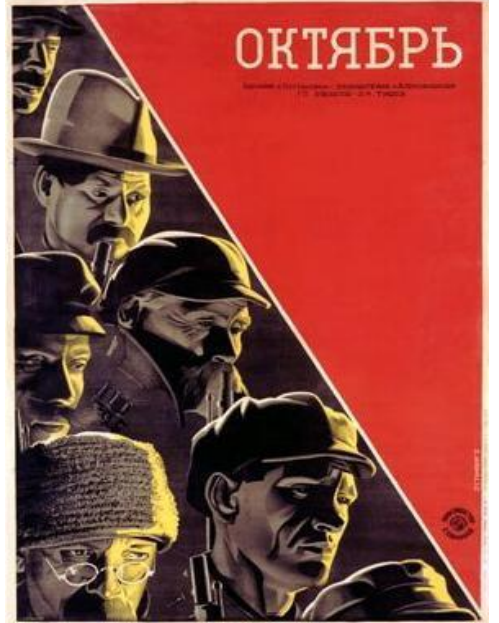

Octubre

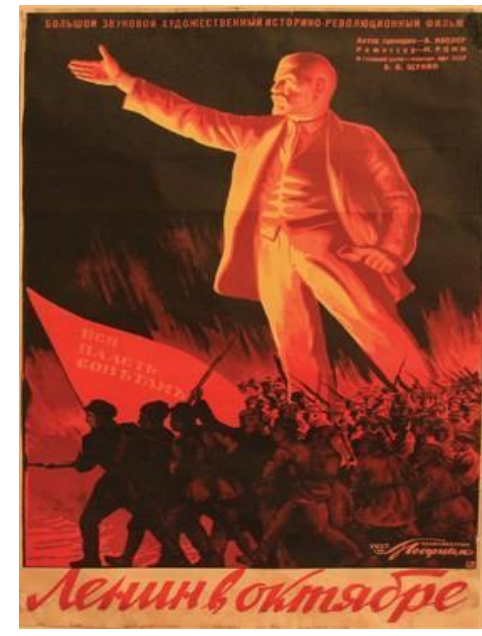

Lenin en Octubre

La llegada a Petrogrado desde Finlandia es narrada de forma diametralmente opuesta en Lenin en Octubre ya que la llegada del líder bolchevique se produce de manera clandestina, sin recibimientos multitudinarios en la estación, ayudado por el

\footnotetext{
${ }^{28}$ LENIN, V. I., Tesis de Abril, en http://www.marxists.org/espanol/lenin/obras/1910s/abril.htm (consultado el $11 / 02 / 2014)$

${ }^{29}$ Octubre, dirigida por Serguéi Eisenstein, URSS, 1928, 103 min., secuencia: 10:20 a 12:03.

${ }^{30}$ Stalin, dirigida por Ivan Passer, EE.UU., 1992, 166 min., secuencia: 03:05 a 05:49.
} 
maquinista para burlar la vigilancia militar ${ }^{31}$, con lo que se ofrece una nueva versión a ese acontecimiento histórico.

Las diferencias entre Octubre, Lenin en Octubre y Stalin son claras. Además de las temporales -las primeras están estrenadas en 1928 y 1937 respectivamente, y la tercera en 1992-, las dos primeras son una loa a la revolución y a su máximo líder, Lenin, mientras que la segunda es una biografía de Stalin. Hay que tener en cuenta a su vez que Octubre y Lenin en Octubre fueron de realización soviética, para conmemorar el décimo y vigésimo aniversario de la revolución, mientras que Stalin es una producción estadounidense, y fue realizada cuando la Unión Soviética había desaparecido.

Conforme fueron pasando las semanas y los meses tras el retorno de Lenin, los bolcheviques fueron ganando apoyos. El famoso lema de los bolcheviques «paz, pan y tierra» sintetizaba a la perfección el sentir general de la población, hastiada de una guerra que no veían como propia y que empeoró sus condiciones de vida.

Los sucesos ocurrían a un ritmo vertiginoso. El intento de golpe de Estado del general Kornilov contra el Gobierno Provisional proporcionó mayor fuerza a los bolcheviques. El soviet más importante, el de Petrogrado, «mostraba una actitud cada vez más crítica con respecto al Gobierno provisional; a su cabeza estaba desde septiembre un bolchevique de reciente incorporación, Lev Bronstein, conocido como Trotski. (...) A los ojos de Lenin estuvieran ya maduras las condiciones para una toma del poder por los soviets respectivos. (...) El 24 de Octubre de 1917 (...) el Gobierno de Kérenski ${ }^{32}$ declaró el estado de sitio, decidió cerrar dos periódicos bolcheviques, ordenó que el ejército ocupase los puntos neurálgicos de la capital. (...) En la noche del 24 al 25, y como respuesta, habían empezado a entrar en acción tropas afines a los bolcheviques y una Guardia Roja que, formada por obreros, se había ido constituyendo en las semanas anteriores. (...) Kérenski no pudo evitar que en unas horas los bolcheviques, cuya presencia en los soviets se había acrecentado sensiblemente, pasasen a controlar Petrogrado. (...) Se eligió un Comité Central Ejecutivo que aprobó la creación de un Consejo de Comisarios del Pueblo (Sovnarkom), encabezado por Lenin y compuesto en exclusiva por bolcheviques» ${ }^{33}$. Se iniciaba así la segunda parte anunciada en las Tesis de Abril. En la toma del poder Trotski «desempeñó un importante papel en la planificación de la operación» ${ }^{34}$.

La toma del Palacio de Invierno por la multitud fue narrada por John Reed en Diez días que estremecieron el mundo, en donde, según Lenin, se narran fielmente los acontecimientos de esos días. Reed relata con gran estilo periodístico la toma del Palacio que vivió en primera persona:

«Gracias a la luz que brotaba de las ventanas del Palacio de Invierno, yo había logrado distinguir que los dos o trescientos primeros eran guardias rojas,

\footnotetext{
${ }^{31}$ Lenin en Octubre, dirigida por Dmitri Vasilyev, URSS, 1937, 108 min., secuencia: 3:47 a 7:00.

${ }^{32}$ Presidente del último gobierno provisional, del Partido Social-revolucionario. En su origen, partido revolucionario campesino y partido de las organizaciones de combate, es decir, de los terroristas. Después de la revolución de febrero, afluyeron a él numerosos contingentes de afiliados, muchos de los cuales no habían sido antes socialistas. Por esta época, los S.R. reclamaban la supresión de la propiedad privada de la tierra, pero mediante indemnización a sus propietarios. El desarrollo del espíritu revolucionario entre los campesinos obligó pronto a abandonar esta cláusula de la indemnización, y los intelectuales más jóvenes y más combativos rompieron con el partido para formar otro nuevo, denominado "socialrevolucionario de izquierda". Los S.R., llamados en adelante por las agrupaciones de izquierda "socialrevolucionarios de derecha", adoptaron la actitud política de los mencheviques y trabajaron de acuerdo con ellos. Acabaron por representar a los campesinos acomodados, los intelectuales y las poblaciones sin educación política de los distritos rurales alejados. En REED, J., 2009, Diez días que estremecieron el mundo, Ed. Diario Público, pág. 25.

33 TAIBO, op. cit., Págs. 38-41.

${ }^{34}$ CARR, E.H., 2009, op. cit., pág. 17.
} 
entre los cuales se hallaban mezclados solamente algunos soldados. Escalamos la barricada de maderos que defendía el Palacio y lanzamos un grito de júbilo al tropezar en el otro lado con un montón de fusiles, abandonados allí por los junkers. A ambos lados de la entrada principal las puertas estaban abiertas de par en par, dejando salir la luz, y ni una sola persona salió del inmenso edificio.

La oleada impaciente de la tropa nos empujó por la entrada de la derecha, la cual conducía a una vasta sala abovedada, de muros desnudos: la bodega del ala Este, de donde partía un laberinto de corredores y escaleras. Guardias rojas y soldados se lanzaron inmediatamente sobre grandes cajas de embalaje que se encontraban allí, haciendo saltar las tapas a culatazos y sacando tapices, cortinas, ropa, vajilla de porcelana, cristalería... Uno de ellos mostraba con orgullo un reloj de péndulo de bronce que llevaba colgado de la espalda. Otro había incrustado en su sombrero una pluma de avestruz. El pillaje no hacía más que comenzar cuando se escuchó una voz: "¡Camaradas, no toquéis nada, no agarréis nada, todo esto es propiedad del pueblo!" Inmediatamente repitieron veinte voces: "¡Alto! ¡Volved a ponerlo todo en su lugar, prohibido agarrar nada, es propiedad del pueblo!" Las manos se abatieron sobre los culpables. Los tejidos de Damasco, las tapicerías, fueron arrebatadas a los saqueadores; dos hombres se hicieron cargo del reloj de bronce. Los objetos, bien o mal, fueron colocados otra vez en sus cajas y algunos de los propios soldados se encargaron de montar la guardia. Esta reacción fue sumamente espontánea. En los corredores y las escaleras, debilitadas por la distancia, se escuchaba repercutir las palabras: "¡Disciplina revolucionaria! ¡Propiedad del pueblo!"

Nos dirigimos a la entrada izquierda, en el ala Oeste. También allí se restablecía el orden.

-¡Evacuad el Palacio!- vociferaba un guardia rojo-. Vamos, camaradas, ¡demostremos que no somos ladrones y bandidos! Todo el mundo fuera de Palacio, con excepción de los comisarios, hasta que se coloquen los centinelas.

Dos guardias rojos, un oficial y un soldado, se mantenían de pie, empuñando un revólver; otro soldado se hallaba sentado en una mesa con pluma y papel. Por todas partes resonaba el grito: "¡Todos fuera! ¡Todos fuera!", y poco a poco toda la tropa comenzó a franquear la puerta hacia el exterior, empujándose, refunfuñando, protestando. Cada uno de los soldados era detenido y registrado, se le vaciaban los bolsillos, se miraba por debajo de su capote. Se le recogía todo lo que "no era ostensiblemente suyo, el secretario tomaba nota y el objeto era llevado a una pequeña habitación vecina.

Fue confiscada así una variedad extraordinaria de objetos: estatuillas, frascos de tinta, colchas bordadas con las iniciales imperiales, candelabros, un bote pequeño de pintura, secantes de escritorio, espadas con puño de oro, pastillas de jabón, vestidos de todas clases, mantas. Un guardia rojo tenía tres fusiles, dos de ellos arrebatados por él a los junkers; otro arrastraba cuatro carteras atestadas de documentos. Los culpables devolvían los objetos de mala gana o se defendían como chiquillos. Los miembros de la comisión de registro, hablando todos a la vez, les explicaban que robar era indigno de los paladines del pueblo. Con frecuencia, aquellos que habían sido sorprendidos daban media vuelta y ayudaban al registro de sus camaradas» ${ }^{35}$.

\footnotetext{
${ }^{35}$ REED, J., 2009, Diez días que estremecieron el mundo, Ed. Diario Público, Págs. 157-159
} 
En el largometraje $\operatorname{Rojos}^{36}$, dirigida por Warren Beatty en 1981, al final de la misma se narra el asalto al Palacio de Invierno de Petrogrado, sin diálogos y con la Internacional como banda sonora. Una gran manifestación bolchevique avanza por la Avenida Nevski en dirección al Palacio, sede del Gobierno Provisional de Kérenski. Una vez que los bolcheviques se hacen con el poder se observa también lo que Reed cuenta en Diez días que estremecieron el mundo sobre los saqueos, cuando se ve a varios guardias rojos llevándose jarrones y candelabros, y como otro guardia hace ademán a uno de aquellos para que deje las cosas en su sitio ${ }^{37}$.
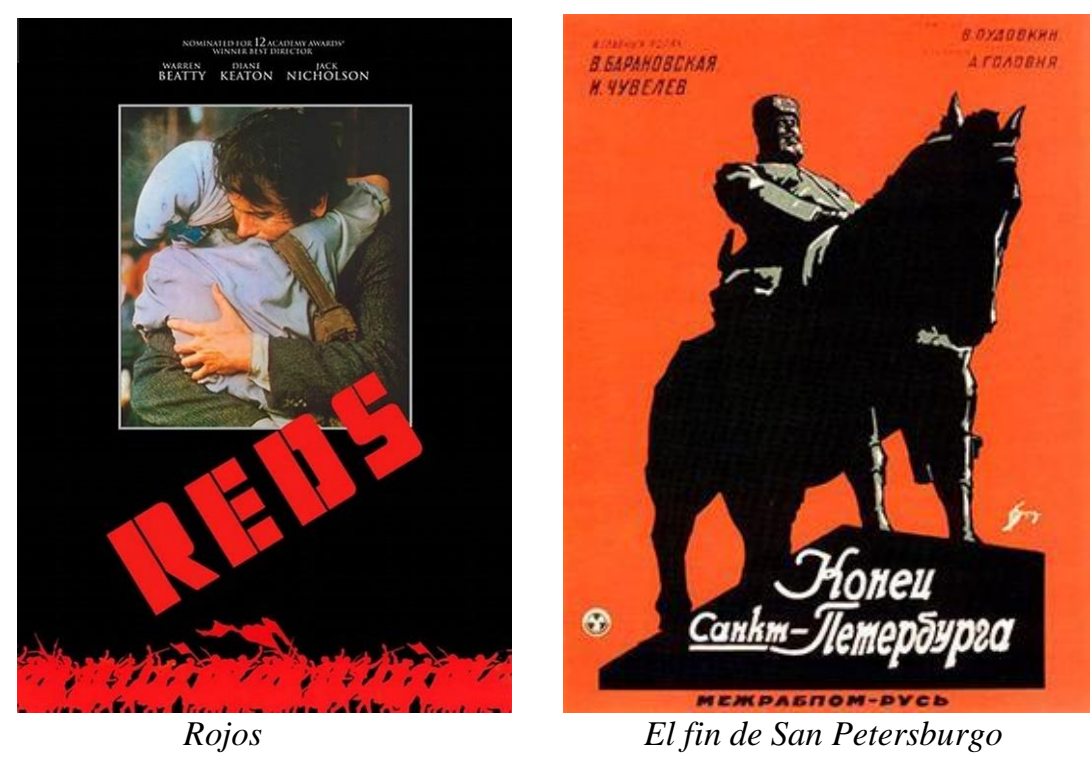

El fin de San Petersburgo

En este caso también se producen grandes diferencias a la hora de exponer el mismo tema en las películas. En Rojos la toma del Palacio se hace de forma breve y sin violencia, mientras que en Octubre se muestra el enfrentamiento armado que se produjo. Además, el papel de Trotski es tratado de diferente forma; si en la primera película aparece como un gran líder, mano derecha de Lenin, en Octubre no aparece en las discusiones del Smolny. No obstante, sí que hay un orador, que se le parece físicamente, y presentado como menchevique, contrario a la toma del poder. Pudiera ser una referencia a Trotski y su pasado menchevique en una época ${ }^{38}$, la del rodaje de Octubre, en la cual empezaba a caer en desgracia al ir perdiendo el enfrentamiento que tuvo con Stalin por el poder tras la muerte de Lenin.

En Lenin en Octubre Trotski ya no aparece. Únicamente se le menciona en un escrito atribuido a Lenin, redactado durante el II Congreso celebrado en el Smolny y anteriormente citado, leído por un dirigente obrero en el cual se les denomina, a Trotski y a Zinoviev, idiota y traidor ${ }^{39}$. Posteriormente, en otra comunicación achacada también a Lenin y leída por ese mismo dirigente, se menciona a Kamenev y a Zinoviev afirmando que pueden fundar un partido con gente igual que ellos para candidatos a la Asamblea Constituyente, pero que los obreros nunca se unirían a su partido ${ }^{40}$. Estos ataques a Kamenev y Zinoviev son debidos a que ambos fueron ejecutados en 1936 durante los Procesos de Moscú, un año antes del estreno de la película. Se muestra tanto a Trotski, como a Kamenev y Zinoviev como personas a las cuales Lenin nunca tuvo en

\footnotetext{
${ }^{36}$ Rojos, dirigida por Warren Beatty, USA, 1981, 200 min, secuencia: 1:37:13 a 1:38:57

${ }^{37}$ Rojos, op. cit., secuencia 1:38:17

${ }^{38}$ Octubre, op. cit., secuencia: 1:25:03 a 1:25:23

${ }^{39}$ Lenin en Octubre, op. cit., secuencia: 9:08 a 10:33.

${ }^{40}$ Ibíd., secuencia: 56:58 a 57:29.
} 
cuenta a la hora de hacer la Revolución, ya que se les consideraba como traidores desde antes del triunfo revolucionario, reescribiendo así la historia y eliminándoles de su participación en la Revolución.

Eisenstein también da cuenta de los saqueos que se produjeron tras la toma del Palacio de Invierno y cómo se realizaron los cacheos de los guardias rojos a sus camaradas para volver lo sustraído ${ }^{41}$. Interesante es de igual modo el protagonismo que se le otorga a Vladímir Antónov-Ovséyenko quien aparece como el conductor de la Guardia Roja en la toma del Palacio y que firma el decreto de derrocamiento del Gobierno Provisional ${ }^{42}$. Antónov-Ovséyenko fue fusilado en 1939 en los Procesos de Moscú acusado de trotskista y su nombre, que aparece claramente en Octubre, desaparece en Lenin en Octubre ya que el personaje que le caracteriza no firma el decreto, por lo que el dirigente pasa a ser un dirigente anónimo, mandándole así al ostracismo junto a los otros tres dirigentes anteriormente citados. No obstante, la entrada de la Guardia Roja en el salón del Gobierno Provisional en Lenin es Octubre es un calco de la realizada en Octubre.

Tras el derrocamiento del Gobierno Provisional, en Octubre aparece Lenin en el Smolny siendo recibido en loor de multitudes, donde se aprueban los decretos de paz y tierra por el congreso de los soviets ${ }^{43}$, escena que se repite de forma milimétrica en Lenin en Octubre $e^{44}$. Octubre es, a su vez, la culminación de la trilogía realizada por Eisenstein sobre la Revolución, tras La huelga y El acorazado Potemkin.

Otra película mítica que narra estos acontecimientos es El fin de San Petersburgo, que fue rodada por encargo del gobierno soviético y cuyo estreno se realizó en el teatro Bolshói el día del décimo aniversario de la Revolución, meses antes que Octubre y que obtuvo una mejor crítica que esta última ${ }^{45}$. En El fin de San Petersburgo se hacen alusiones a la Primera Guerra Mundial, mostrando imágenes de las duras condiciones en las que vivían los soldados, soportando frío y fuertes aguaceros, en contraposición a la vida fácil y acomodada de la aristocracia zarista, que veían la guerra como un modo de frenar el ambiente prerrevolucionario que se vivía ya en Rusia. Muestra además de forma nítida la relación entre la guerra y el capital al entrelazar a los soldados que avanzan en el frente con los brokers abalanzándose en la bolsa, mostrando la violencia de la guerra y la actitud capitalista en la bolsa como las dos caras de una misma moneda ${ }^{46}$.

Posteriormente se muestra el descontento popular ante la escasez de productos de primera necesidad como el pan y la llega al poder del Gobierno Provisional, tras la revolución de febrero, al cual se muestra alejado de la realidad ${ }^{47}$. Un mitin obrero sirve como metáfora de lo que ocurriría en los meses posteriores, en donde un obrero lanza consignas a favor de los soviets y contra la guerra cuando un burgués sube al escenario y se enzarza en una pelea con el obrero, ganando este último y cayendo el burgués, metáfora de lo que pasaría en el mes de octubre ${ }^{48}$. La unión del ejército a los soviets y a la revolución bolchevique se escenifica cuando un oficial ordena disparar a una unidad contra «los traidores», un bolchevique y un soldado junto a aquel, y cuando los soldados del pelotón abren fuego a quien fusilan es al oficial, y el resto de los soldados de la compañía disparan contra los oficiales que había allí, los cuales huyen del lugar ${ }^{49}$.

\footnotetext{
${ }^{41}$ Octubre, op. cit., secuencia: 1:40:57 a 1:42:10

${ }^{42}$ Ibíd., secuencia: 1:37:58 a 1:40:20

${ }^{43}$ Ibíd., secuencia: 1:40:57 a 1:42:10

${ }^{44}$ Lenin en Octubre, op. cit., secuencia: 1:34:55 a 1:36:44.

${ }^{45}$ BERGAN, op. cit., Págs. 162-163.

${ }^{46}$ El fin de San Petersburgo, dirigida por Vsevolod Pudovkin, URSS, 1927, 74 min., secuencia: 44:32 a 58:28.

${ }^{47}$ Ibíd., secuencia: 59:03 a 1:01:36.

${ }^{48}$ Ibíd., secuencia: 1:03:00 a 1:04:04.

${ }^{49}$ Ibíd., secuencia: 1:12.50 a 1:15.07.
} 
La gran diferencia entre Octubre y El fin de San Petersburgo es la forma en que ambas películas enfocan la Revolución de Octubre, sobre todo en el momento de la toma del Palacio de Invierno. El fin de San Petersburgo tiene un enfoque diferente al de Eisenstein ya que no hay grandes masas luchando en la toma, ni se aprecia la intriga ni la tensión de la que hace gala Octubre. Por el contrario, en El fin de San Petersburgo se da mayor importancia, ya que aparece más veces en mucho menor tiempo, al Acorazado Aurora y a los guardias rojos que permanecían en la Fortaleza de Pedro y Pablo ${ }^{50}$. Tampoco aparecen ninguno de los grandes líderes de la Revolución, sino que el objetivo se centra en el pueblo que realiza la gesta y el cambio de época, escenificado en la mujer que va en busca de su marido con unas pocas patatas, las cuales reparte entre varios guardias rojos mostrando los nuevos valores de la Revolución, en la que la solidaridad prima por encima de todo ${ }^{51}$.

La misma forma de narrar el disparo del Acorazado Aurora, así como la toma del Palacio de Invierno que ocurre en El fin de San Petersburgo se observa en Lenin en Octubre, con la única salvedad que en ésta se reproducen combates dentro del Palacio de Invierno ${ }^{52}$. En esta última, durante la toma del Palacio, una vez dentro, hay una secuencia que recuerda a la Escalinata de Odesa de El Acorazado Potemkin.

\section{Conclusiones}

Para Carr, la revolución de 1917 «fue la primera revolución de la historia empeñada en establecer la justicia social por medio de controles de la economía organizados por la acción política» ${ }^{53}$.

Gramsci, tras el triunfo de Octubre, hizo una reflexión certera acerca del carácter socialista de la revolución en el ámbito ideológico. Con una visión antidogmática del marxismo afirmó que «la revolución de los bolcheviques se compone más de ideologías que de hechos. (...) Es la revolución contra El Capital de Carlos Marx. (..) Era la demostración crítica de la necesidad ineluctable de que en Rusia se formase una burguesía, se iniciase una era capitalista, se instaurase una civilización de tipo occidental, antes de que el proletariado pudiera siquiera pensar en su insurrección, en sus reivindicaciones de clase, en su revolución. Los hechos han superado las ideologías. Los hechos han reventado los esquemas críticos según los cuales la historia de Rusia hubiera debido desarrollarse según los cánones del materialismo histórico. Los bolcheviques reniegan de Carlos Marx al afirmar, con el testimonio de la acción desarrollada, de las conquistas obtenidas, que los cánones del materialismo histórico no son tan férreos como se pudiera pensar y se ha pensado» ${ }^{54}$.

Acerca de la filmografía soviética analizada se pueden extraer dos grandes conclusiones: la primera es que, pese a tratarse de unas películas de claro carácter histórico poseen también una gran dosis de propaganda política, en donde la lucha de clases y el triunfo revolucionario son el centro de las mismas. Del mismo modo, y como segunda conclusión, el cine conmemorativo soviético respondía a la coyuntura política, tal y como se aprecia en la filmografía del vigésimo aniversario en donde ya no aparecen los dirigentes bolcheviques expulsados o condenados en los Procesos de Moscú.

\footnotetext{
${ }^{50}$ El fin de San Petersburgo, op. cit., secuencia: 1:15:10 a 1:20:28.

${ }^{51}$ Ibíd., secuencia: 1:24:00 a 1:25:20.

${ }^{52}$ Lenin en Octubre, op. cit., secuencia: 1:26:36 a 1:36:45.

${ }^{53}$ CARR, E. H., 1985, op. cit., pág. 39.

${ }^{54}$ GRAMSCI, A., 1917 La revolución contra el capital, en http://www.marxists.org/espanol/gramsci/nov1917.htm (consultado el 17/02/2014)
} 
Este importante acontecimiento histórico, que marcó en gran medida el devenir de los decenios siguientes, tiene en las películas analizadas anteriormente un gran impacto. Sirven a su vez para comprender cómo se veía la Revolución de Octubre en la URSS y qué imagen se quería dar de aquella -a excepción de Rojos y Stalin-. La producción cinematográfica siempre ha estado al servicio de unos intereses, pero ello no es óbice para reconocer la calidad de las películas analizadas, algunas de las cuales pertenecen, por mérito propio, al selecto grupo de obras maestras de la historia cinematográfica mundial.

\section{Fuentes}

\section{Bibliografía}

ANDRADE, J., y HERNÁNDEZ, F., 2017, 1917. La Revolución rusa cien años después, Ed. Akal, Madrid.

BERGAN, R., 2001, Serguéi Eisenstein. Una vida en conflicto, Ed. Alba, Barcelona.

CARR, E. H., 1985, 1917. Antes y después (la revolución rusa), Ed. Sarpe, Madrid.

CARR, E. H., 2009, La revolución rusa. De Lenin a Stalin (1917-1929), Alianza Editorial, Madrid.

DE PABLO, S. (ed.), La historia a través del cine: La Unión Soviética, EHU/UPV, Zarautz.

GRAMSCI, A., 1917 La revolución contra el capital, en http://www.marxists.org/espanol/gramsci/nov1917.htm.

GRAMSCI, A., 1917, Notas sobre la revolución rusa, en http://www.marxists.org/espanol/gramsci/abr1917.htm.

HILL, C., 2017, La Revolución Rusa, Ed. Ariel, Barcelona.

HOBSBAWM, E., 1994, Historia del siglo XX, Ed. Crítica, Buenos Aires.

HOBSBAWM, E., 2009, La era del imperio. 1875-1914, Ed. Crítica, Barcelona.

LENIN, V. I., Tesis de Abril, en http://www.marxists.org/espanol/lenin/obras/1910s/abril.htm.

MARX, K. y ENGELS, F., 1987, El manifiesto comunista, ALBA, Madrid.

REED, J., 2009, Diez días que estremecieron el mundo, Ed. Diario Público.

SABORIDO, J., 2006, La revolución rusa, Ed. Dastin, Madrid.

SERGE, V., 2017, El año I de la Revolución rusa, Ed. Traficantes de Sueños, Madrid.

TAIBO, C., 2010, Historia de la Unión Soviética 1917-1991, Alianza Editorial, Madrid.

TROTSKI, L., 2017, Historia de la Revolución Rusa, Ed. Talaparta, Tafalla.

TROTSKI, L., “1905”, Mi vida, en http://www.marxists.org/espanol/trotsky/1930s/mivida/index.htm.

\section{Filmografía}

- El acorazado Potemkin, dirigida por Serguéi Eisenstein, URSS, 1925, 77 min. 
$\min$.

- El fin de San Petersburgo, dirigida por Vsevolod Pudovkin, URSS, 1927, 74

- Lenin en Octubre, dirigida por Dmitri Vasilyev, URSS, 1937, 108 min.

- Octubre, dirigida por Serguéi Eisenstein, URSS, 1928, 103 min.

- Rojos, dirigida por Warren Beatty, USA, 1981, 200 min.

- Stalin, dirigida por Ivan Passer, EE.UU., 1992, 166 min.

MIKEL BUENO URRITZELKI es licenciado en Historia por la Universidad del País Vasco, actualmente es doctorando de Historia en la Universidad Pública de Navarra. Ha colaborado en varias obras colectivas, así como en artículos en diversas revistas. Asimismo, ha participado en diversos congresos, tanto nacionales como internacionales.

email— mikelbueno1984@gmai.com 
FILMHISTORIA Online Vol. 29, núms. 1-2 (2019) · ISSN: 2014-668X 